Dr Kaneko discloses a financial relationship with Edwards Lifesciences. All other authors have nothing to disclose with regard to commercial support.

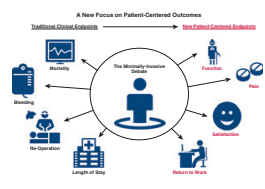

\section{PATIENT-REPORTED OUTCOMES: HOW TO ADVANCE THE MINIMALLY INVASIVE DEBATE}

\section{To the Editor:}

Since their introduction 2 decades ago, minimally invasive techniques for aortic valve replacement have been a topic of research and debate among cardiac surgeons. Proponents of minimally invasive approaches argue the ability to deliver similar clinical outcomes with improved cosmesis and reduced resource use. ${ }^{1}$ Critics point to longer operative times and criticize increased complexity without reproducible improvements in overall morbidity and mortality. ${ }^{2}$

In an effort to settle this debate, Nair and colleagues ${ }^{3}$ presented results of the Mini-Stern Trial in the December 2018 issue of the Journal. In a study of 222 patients randomly allocated across 2 sites in the United Kingdom, Nair and colleagues ${ }^{3}$ found that aortic valve replacement through an upper ministernotomy (MS) did not result in shorter stay, faster recovery, or improved survival relative to full sternotomy. MS was also associated with an increased cost of $£ 1714$ per patient, which appeared largely driven by increased perioperative expenses.

We read this study with interest, but we question its generalizability in context of previous research in the field. Mean hospital stay was long in both groups (9.5 days in the MS group vs 8.6 days in the full sternotomy group), which Nair and colleagues ${ }^{3}$ attributed partially to exogenous systemic factors. This finding, along with the increased cost, runs contrary to other large experiences. $^{4-6}$ Several methodologic factors may have influenced this surprising outcome. First, when patient and provider blinding is not possible, some of the benefits of randomization are lost. Second, because of the intention-to-treat design, some patients who crossed over from MS to full sternotomy remained counted as

\footnotetext{
The Editor welcomes submissions for possible publication in the Letters to the Editor section that consist of commentary on an article published in the Journal or other relevant issues. Authors should: • Include no more than 500 words of text, three authors, and five references. • Type with double-spacing. • See http://jtcs.ctsnetjournals.org/ misc/ifora.shtml for detailed submission instructions. • Submit the letter electronically via jtcvs.editorialmanager.com. Letters commenting on an article published in the JTCVS will be considered if they are received within 6 weeks of the time the article was published. Authors of the article being commented on will be given an opportunity of offer a timely response ( 2 weeks) to the letter. Authors of letters will be notified that the letter has been received. Unpublished letters cannot be returned.
}

MS, despite the addition of more complex aortic or coronary procedures. Nair and colleagues ${ }^{3}$ note that surgeons were experienced in performing both procedures; however, they did not quantify this experience. On the basis of literature from the mitral space, we know that a learning curve often exists for minimally invasive procedures. ${ }^{7,8}$ Finally, the study was not powered to make definitive inferences about postoperative pain or patient-reported outcomes, which are increasingly valuable in this debate.

Despite these limitations, Nair and colleagues ${ }^{3}$ are to be commended for a rigorous and interesting trial. Their conclusions present an opportunity to rethink how we frame the minimally invasive discussion and how we define new important clinical end points. As long as there remains equipoise with respect to the traditional morbidity and mortality measures, the debate between sternotomybased and minimally invasive aortic valve replacement may never be settled otherwise. Furthermore, as we reduce adverse events overall, our ability to show superiority of any technique will decrease. In the transcatheter space, for instance, trials powered for noninferiority will continue to inform guidelines that place increased importance on patient values and preferences. ${ }^{9}$ This raises the question of why we are not measuring these metrics in the context of surgery. As we continue to expand our armamentarium of treatment options, this reliance on patient experience and preference in clinical decision making will be increasingly pertinent. In the coming era, it will be more important than ever to focus on patient experience and patient-reported outcomes, to benchmark against traditional operative techniques.

Edward D. Percy, $M D$

Sameer A. Hirji, MD

Tsuyoshi Kaneko, $M D$

Marc P. Pelletier, MD, MSc

Division of Cardiac Surgery

Department of Surgery

Brigham and Women's Hospital

Harvard Medical School

Boston, Mass

\section{References}

1. Malaisrie SC, Barnhart GR, Farivar RS, Mehall J, Hummel B, Rodriguez E, et al Current era minimally invasive aortic valve replacement: techniques and practice. J Thorac Cardiovasc Surg. 2014;147:6-14.

2. Gilmanov D, Bevilacqua S, Murzi M, Cerillo AG, Gasbarri T, Kallushi E, et al Minimally invasive and conventional aortic valve replacement: a propensity score analysis. Ann Thorac Surg. 2013;96:837-43.

3. Nair SK, Sudarshan CD, Thorpe BS, Singh J, Pillay T, Catarino P, et al Mini-Stern trial: a randomized trial comparing mini-sternotomy to full median sternotomy for aortic valve replacement. J Thorac Cardiovasc Surg. 2018;156: 2124-32.e31.

4. Neely RC, Boskovski MT, Gosev I, Kaneko T, McGurk S, Leacche M, et al, Minimally invasive aortic valve replacement versus aortic valve replacement 
through full sternotomy: the Brigham and Women's Hospital experience. Ann Cardiothorac Surg. 2015;4:38-48.

5. Ghanta RK, Lapar DJ, Kern JA, Kron IL, Speir AM, Fonner E Jr, et al. Minimally invasive aortic valve replacement provides equivalent outcomes at reduced cost compared with conventional aortic valve replacement: a real-world multi-institutional analysis. J Thorac Cardiovasc Surg. 2015;149:1060-5.

6. Johnston DR, Atik FA, Rajeswaran J, Blackstone EH, Nowicki ER, Sabik JF III, et al. Outcomes of less invasive J-incision approach to aortic valve surgery. J Thorac Cardiovasc Surg. 2012;144:852-8.e3.

7. Hawkins RB, Ailawadi G. Institutional or individual experience matters in minimally invasive valve surgery. J Thorac Cardiovasc Surg. 2016;152:1477-8.

8. Holzhey DM, Seeburger J, Misfeld M, Borger MA, Mohr FW. Learning minimally invasive mitral valve surgery: a cumulative sum sequential probability analysis of 3895 operations from a single high-volume center. Circulation. 2013;128:483-91.

9. Nishimura RA, Otto CM, Bonow RO, Carabello BA, Erwin JP III, Fleisher LA, et al. 2017 AHA/ACC focused update of the 2014 AHA/ACC guideline for the management of patients with valvular heart disease: a report of the American College of Cardiology/American Heart Association task force on clinical practice guidelines. J Am Coll Cardiol. 2017;70:252-89.

https://doi.org/10.1016/j.jtcvs.2019.01.052

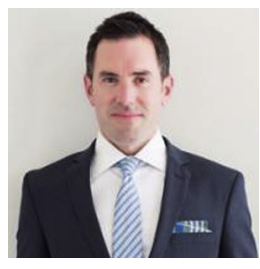

MINIMALLY INVASIVE CARDIAC SURGERY AND THE IMPORTANCE OF QUALITATIVE PATIENT-CENTERED METRICS TO GUIDE INNOVATIONS

\section{Reply to the Editor:}

As transcatheter aortic valve replacement (AVR) has grown, and the benefits of percutaneous techniques have been realized, surgeons have explored less invasive approaches to perform surgical AVR (SAVR). Some argue that minimally invasive SAVR is the optimal approach, because it minimizes surgical trauma while achieving complete resection of a diseased aortic valve, as opposed to crushing it by transcatheter AVR deployment. ${ }^{1}$ Interestingly, a recent randomized trial by Nair and colleagues $^{2}$ demonstrated no apparent clinical benefits with minimally invasive SAVR at the expense of increased costs. The results of that study and Fedak's recent editorial ${ }^{3}$ have fueled further debate as to whether there is any advantage to minimally invasive techniques at all.

The letter by Percy and colleagues is of particular interest. We agree with the argument that it is difficult to show differences in safety and efficacy outcomes between ministernotomy and full sternotomy AVR. In experienced hands, both approaches are likely safe and effective when compared for traditional clinical end points. We must be cautious, however, and not dismiss emerging unvalidated minimally invasive techniques if they fail to demonstrate superiority when assessed by these end points. Qualitative measures may be important to assess further the values, beliefs, and attitudes of patients who must choose from a variety of interventions, including transcatheter AVR.
More qualitative outcome measures, such as pain, functional disability, and overall patient satisfaction, may be more valuable to assess the subtle but still relevant differences between equally safe and effective operative techniques. We must encourage such end points in the design of our clinical studies to evaluate minimally invasive approaches. The time to full physical and mental recovery after open- surgery is meaningful to patients but often underappreciated by caregivers. Much of the limitation to early functional recovery after SAVR involves activity restrictions related to sternal precautions. These restrictions limit mobility, activity, return to work, and patient satisfaction. The right anterior minithoracotomy approach for mini-SAVR is established and described. ${ }^{4}$ In our growing experience with right anterior minithoracotomy, we find that patients have minimal postoperative pain, need infrequent blood transfusion, and are often discharged early. By avoiding sternal precautions, they can return to physical activity much earlier. To date, experience with this technique is limited, and robust outcome data are lacking, but reports from high-volume centers with expertise in right anterior minithoracotomy are encouraging. ${ }^{5}$

Avoiding sternal precautions is an important goal to achieve after SAVR. This simple and straightforward patient-centered target may have the greatest potential to accelerate functional recovery and provide optimal patient satisfaction. We will develop a rigorous multimodal research platform to explore innovations to enhance and accelerate recovery after heart surgery. Our work will be guided by qualitative outcomes as primary end points. We use a right anterior mini thoracotomy approach for mini-SAVR for complete sternum sparing, which facilitates enhanced functional recovery. For redo operations or for those patients who are not candidates for mini-SAVR, we continue to develop adhesive-enhanced sternal closure methods, with a novel bone adhesive compound to achieve rapid bony stabilization and eliminate the need for sternal precautions (NCT03365843). ${ }^{6,7}$

William D. T. Kent, $M D, M S c$ Paul W. M. Fedak, MD, PhD, FRCS(C)

Section of Cardiac Surgery

Department of Cardiac Sciences

Cumming School of Medicine

University of Calgary

Calgary, Alberta, Canada

Libin Cardiovascular Institute of Alberta Calgary, Alberta, Canada

\section{References}

1. Glauber M, Miceli A. Minimally invasive aortic valve replacement with sutureless valve is the appropriate treatment option for high-risk patients and the "real alternative" to transcatheter aortic valve implantation. J Thorac Cardiovasc Surg. 2016;151:610-3. 